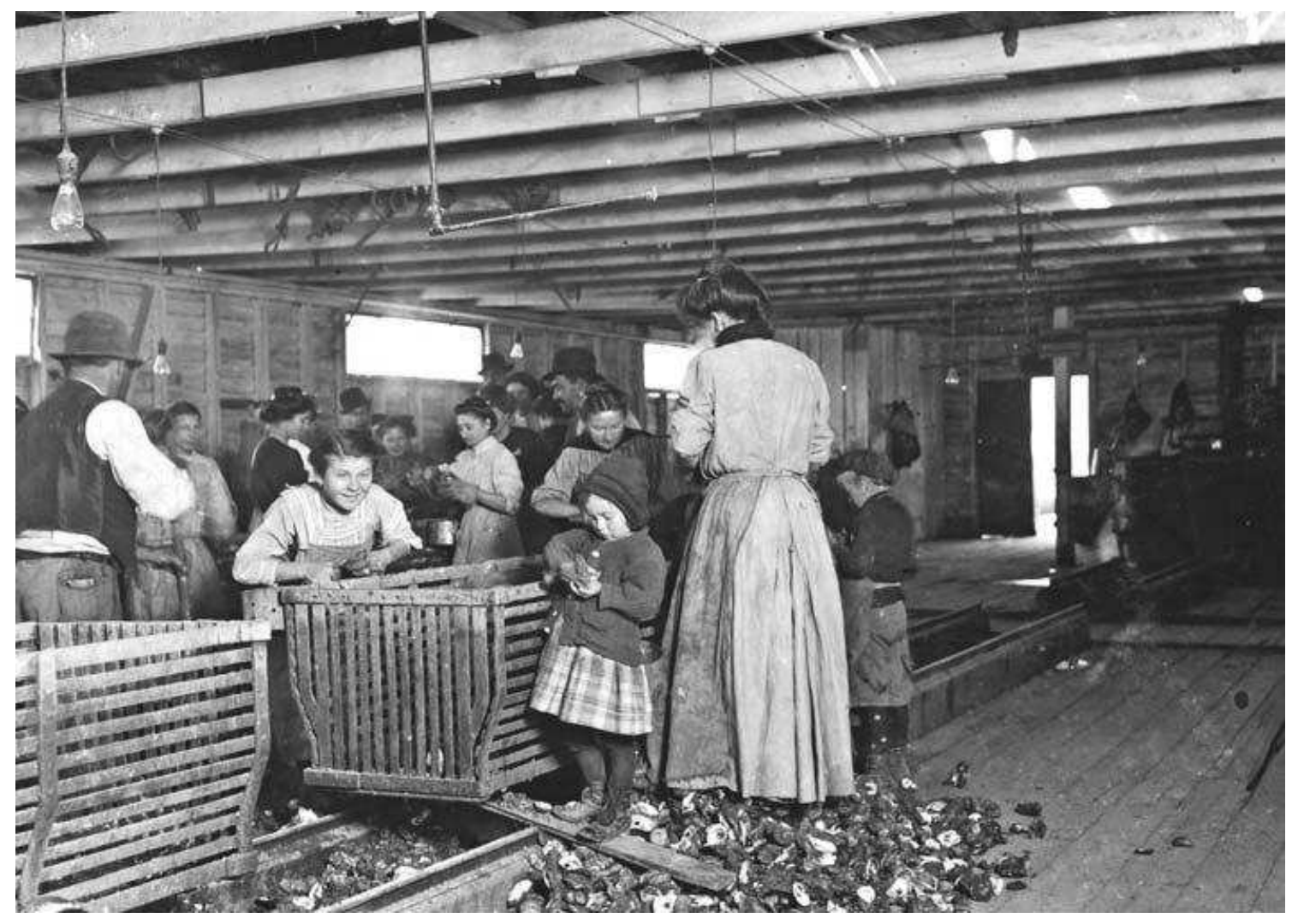

Trabalhadores de Dunbar, Lewis Hine (1874-1940), Louisiana, EUA, 1911. 


\title{
Trabalho e responsabilidades familiares no Brasil: reflexões sobre os direitos do trabalho
}

\author{
Work and family responsibilities in Brazil: reflections \\ on labour rights
}

\section{Andréa de Sousa Gama*}

\begin{abstract}
Resumo: Entender a relação entre trabalho e vida familiar, no capitalismo, requer reconhecer que essas dimensões estão em conflito, adquirindo novos contornos com a maciça entrada feminina no mercado de trabalho. A feminização dos mercados de trabalho coincidiu com a transformação da organização do trabalho e da produção, incrementando essas tensões. A estas mudanças se associam as sociodemográficas que geraram variações na estrutura das famílias, criando uma nova relação entre demanda e oferta de cuidados. No artigo é analisada a evolução da legislação trabalhista e previdenciária quanto à proteção à maternidade e a "conciliação" entre trabalho e família, tendo por referência normas internacionais de proteção ao(à) trabalhador(a) e o exame de proposições recentes do legislativo brasileiro. Considera-se, desde uma perspectiva de gênero, que a produção desta legislação reflete possibilidades e limites das formas de intervenção do Estado brasileiro sobre a temática.
\end{abstract}

Palavras-chave: trabalho e responsabilidades familiares; direitos do trabalho; gênero e trabalho.

\begin{abstract}
Understand the relationship between work and family life under capitalism requires recognizing that these dimensions are in conflict, acquiring new contours with the massive entry of women in the labor market.The feminization of labor markets coincided with the transformation of the organization of work and production and increased those tensions. Besides changes in the productive sphere, socio-demographic changes have generated variations in the structure of families, creating a new relationship between demand and supply of care. The article analyzes the evolution of labor legislation and social security protection as motherhood and "reconciliation" between work and family, having as reference international standards of labor law and examines recent Brazilian legislative propositions. We consider that the production of this legislation reflects the possibilities and limits of the forms of state intervention on the Brazilian theme, from a gender perspective.
\end{abstract}

Keywords: work and family responsibilities; labor rights; gender and work.

\footnotetext{
* Assistente social, mestre e doutora em Saúde Coletiva pela Escola Nacional de Saúde Pública Sergio Arouca da Fundação Oswaldo Cruz (ENSP/FIOCRUZ) e professora adjunta da Faculdade de Serviço Social da Universidade do Estado do Rio de Janeiro (FSS/UERJ). Correspondência: Rua São Francisco Xavier, 524, Pavilhão João Lyra Filho. 8o andar, Bloco D, Sala 8020. CEP: 20550-013, Maracanã - Rio de Janeiro/RJ - Brasil. E-mail: <andreasgama@gmail. com>.
} 


\section{Introdução}

As últimas três décadas foram marcadas por mudanças no mercado de trabalho e na estrutura das famílias, agravando os problemas relativos às relações entre o trabalho e a vida familiar. No Brasil, a participação feminina no mercado de trabalho cresceu independente dos cenários econômicos recessivos ou expansivos. Além de responder às dificuldades econômicas das famílias, que levaram as casadas a procurar emprego, mudanças culturais relacionadas aos papéis de gênero - valores de independência e autonomia financeira das mulheres - não podem ser desconsideradas. (BRUSCHINI; LOMBARDI, 2003). Com o crescimento da participação de ambos os cônjuges no mercado de trabalho amplia-se o contingente de famílias que têm o desafio de dar conta das demandas relativas ao trabalho e às responsabilidades familiares. Além das mudanças no mercado de trabalho, profundas mudanças sociodemográficas também estão ocorrendo, as quais geram variações na organização interna das famílias, criando uma nova relação entre demanda e oferta de cuidados. Apesar dessas mudanças, não ocorreram rupturas significativas nas concepções culturais predominantes que consideram a reprodução social uma responsabilidade das mulheres e não uma necessidade da sociedade.

A maior diferenciação dos arranjos familiares cria "novas" necessidades e expectativas em relação ao Estado. Dentre elas, temos os conflitos entre trabalho e vida familiar, que engloba a equalização do trabalho doméstico, a educação das crianças, a atenção aos idosos - especialmente sob a perspectiva de maior longevidade e tamanhos menores de família - e o cuidado aos doentes. O exaurimento das formas pelas quais as famílias tentam equacionar essas tensões não tem produzido novas formas de políticas públicas direcionadas a este fim, principalmente se levarmos em conta as mudanças no mercado de trabalho e o impacto do ideário neoliberal nas políticas sociais que sobrecarrega ainda mais as famílias na responsabilização pelas necessidades da reprodução social.

Nesse cenário, como o desenvolvimento dos direitos do trabalho no Brasil tem respondido ao conflito entre trabalho remunerado e responsabilidades familiares, considerando esta política pública como um mecanismo importante neste enfrentamento? Mediante as mudanças mencionadas, realizamos a análise sobre a legislação trabalhista/previdenciária existente e em proposição, a partir do exame da concepção, do acesso e da estrutura de benefícios, tendo como referência uma perspectiva de igualdade de gênero.

\section{Breves apontamentos sobre o conflito trabalho e vida familiar na produção/reprodução social capitalista}

No seio de toda formação social coexistem uma produção social de bens e uma produção social de seres humanos, que são sempre distintas, 
mas, ao mesmo tempo, relacionadas uma à outra. Compreendidas dessa forma, a produção e a reprodução são indissociáveis.

O advento do modo de produção capitalista subverte as condições de produção material, mas também as condições de produção de seres humanos. Esse modo de produção enseja uma nova concepção de trabalho e de reprodução social: o trabalho como uma atividade que pode ser objetificada, mediada pela relação de assalariamento que se desenrola em torno da apropriação do tempo do assalariado pelo capitalista, constituindo interesses de diferentes classes sociais. Esta relação de assalariamento também estabelece uma série de alterações na relação entre produção e reprodução social, como: o contrato sexual (PATEMAN, 1993), a invisibilidade do trabaIho reprodutivo, o status inferiorizado das mulheres e o teor e a natureza das relações familiares. Estas passam a ser vistas e interpretadas como uma unidade de consumo, subsumidas e separadas de maneira desigual, de forma que a produção tenha maior importância do que a reprodução social. Esse processo se espraia pelo conjunto das relações sociais, atingindo inclusive o processo de conhecimento científico.

A noção de reprodução da força de trabalho no interior da produção capitalista fornece a moldura para se pensar os atributos da reprodução social. Entretanto, o modus operandi da reprodução social nessa lógica de organização social apresenta nuances e características que precisam ser decompostas, a fim de dar conta da sua complexidade. A mercantilização da vida social nas relações sociais capitalistas atinge essas dimensões de maneira diferenciada; no âmbito da produção, a extração de mais valor e no âmbito da reprodução social, a produção indireta de mais valor pela não mercantilização do trabalho doméstico realizado gratuitamente pelas mulheres no interior das famílias.

A família e o Estado são mecanismos indiretos de produção de mais-valia pela divisão do custo social de exploração da força de trabalho. Na família, este custo é invisibilizado, naturalizado socialmente e absorvido iminentemente pelas mulheres. $\mathrm{O}$ preço de mercado da força de trabalho, portanto, é constituído pela parte paga da extração da mais-valia e pela parte não paga produzida pelo trabalho doméstico não remunerado das mulheres. Este participa da produção de valor pelo seu papel na reprodução da força de trabalho, bem como no seu papel socializador na sociabilidade capitalista. Atualmente trabalha-se, inclusive, com a categoria de jornada de trabalho total, composta pelo tempo de trabalho doméstico e pela jornada de trabalho assalariado na produção de trabalho excedente, apesar de todas as dificuldades para quantificar e qualificar a jornada de trabalho doméstico. Ademais, outro elemento de caráter ideológico se apresenta, que é a noção de trabalho doméstico não remunerado concebido como o oposto da objetificação. Essa noção está ligada às relações afetivas no interior da família e baseada na disponibilidade de tempo das mulheres. Sendo a forma privilegiada de expressão do "amor" na esfera dita "privada", os ges- 
tos repetitivos e os atos cotidianos de manutenção do lar, da saúde e da educação de crianças, idosos e doentes são naturalizados e atribuídos às mulheres. Nos debates sobre o tema, a existência de uma perpétua hesitação entre o trabalho assalariado, de um lado, e o trabalho doméstico, de outro, nada mais é do que um indicador de que essas duas questões se interpenetram sem, no entanto, se confundirem. A partir dessa compreensão da produção e da reprodução social podemos ancorar o conflito que se estabelece entre essas esferas e destacar a necessidade de romper com uma lógica de separação do "mundo do trabalho" e do "mundo da cultura" (família). Assim, não há como existir um processo social de produção apartado da reprodução da vida social - ambos são momentos diferenciados, mas não autônomos, de uma mesma forma social.

O assalariamento não atingiu os homens e as mulheres da mesma maneira. Esse movimento uniformizou os indivíduos pela redução de sua força de trabalho ao salário, mas aprofundou a especificidade das mulheres e estabeleceu uma relação de desigualdade. $\mathrm{O}$ acesso das mulheres ao assalariamento jamais suprimiu essa especificidade, no sentido em que se poderia pensar que, como assalariada, a mulher já não se distingue mais do homem. (McINTOSH, 2000). Ao invés disto, observam-se múltiplas divisões se criarem e se reproduzirem entre homens e mulheres no interior do trabalho remunerado. Igualmente, verifica-se a pouca variabilidade da divisão sexual do trabalho doméstico. E isto, apesar dos movimentos feministas visando transformar essas relações! Se o problema ocorresse com um indivíduo que antes de tudo trabalha, soluções de organização seriam suficientes para resolver o problema da questão feminina, permanecendo-se no seio de uma dimensão de trabalho remunerado. Mas, justamente porque a questão feminina não está separada da dimensão familiar, a solução não se encontrará somente em conteúdos profissionais ou no fato de "conciliar" os papéis, mas em uma redefinição global da relação de subordinação da reprodução social à produção na sociedade capitalista, como uma ação que conjuga de forma sincrética, as relações no trabalho e na família.

Contemporaneamente, as mudanças na organização e no perfil da produção, bem como as transformações no papel e função das famílias, ensejada pela globalização capitalista e pela reestruturação produtiva, fazem surgir novas contradições e roupagens para as desigualdades entre homens e mulheres, tanto no mercado de trabalho, quanto na família. A reestruturação produtiva introduziu um padrão de flexibilidade nas relações de trabalho, através, principalmente, do recurso ao trabalho feminino.

Os efeitos da globalização afetaram desigualmente o emprego masculino e feminino nos anos 1990. (HIRATA, 2002; MELO, 1998). Se o emprego masculino regrediu ou estagnou, a liberalização do comércio e a intensificação da concorrência internacional tiveram como consequência um aumento do emprego e do trabalho remunerado das mulheres em nível mundial. Notou-se um crescimento da participação das mulheres no mer- 
cado de trabalho, nas áreas formais e informais da atividade econômica, assim como no setor de serviços. Isso vem provocando uma tendência de maior aproximação nas características de inserção no trabalho entre homens e mulheres. Entretanto, essa participação se traduz em empregos vulneráveis, caracterizados pela precariedade - trabalho parcial, sazonal, temporário (nos países capitalistas desenvolvidos) e trabalho informal, empregos em meio período (países em vias de desenvolvimento). (HIRATA, 2002). Importante destacar que elas, as mulheres, aumentam sua participação no mercado de trabalho exatamente em um contexto de perda de direitos sociais. Além disto, em maior convergência ou não, as tensões da igualdade de gênero permanecem, porque as forças que impelem a convergência também criam e aprofundam desigualdades de segunda ordem, particularmente, os obstáculos relacionados com a segregação e discriminação de gênero no mercado de trabalho, condições precárias no trabalho e a divisão desigual do trabalho doméstico. Todas essas mudanças incrementaram as tensões entre o trabalho remunerado e as responsabilidades familiares.

Tendo em vista o percurso trilhado, o objetivo principal deste estudo é analisar as normas legais que guardam relação com a questão do conflito entre trabalho e responsabilidades familiares no Brasil. Examinamos a legislação trabalhista e previdenciária que prevê uma série de medidas de proteção à maternidade e à "conciliação" entre trabalho e família e suas mudanças recentes, verificando os direitos, as contrapartidas e a cobertura dos benefícios e comparando a legislação nacional com a internacional. Desenvolvemos, também, uma sistematização dos projetos de lei em tramitação no Congresso Nacional, no período compreendido entre 1994 e 2010, com o intuito de mapear o estado da arte das proposições do legislativo brasileiro quanto ao tema, tendo como parâmetro normativo a concepção de igualdade de gênero.

Trabalhamos iminentemente com a pesquisa documental, examinando os textos legais e os documentos governamentais. Dois tipos diferenciados de textos jurídicos foram analisados, os constitucionais e os regulamentares. Tendo como base a Constituição Brasileira (BRASIL, 1990) e a Consolidação das Leis do Trabalho (CLT) (BRASIL, 2010) comparamos a legislação nacional com os documentos e normativas da Organização Internacional do Trabalho (OIT) referente à Proteção da Maternidade e aos (às) Trabalhadores (as) com Responsabilidades Familiares.

\section{Resultados e discussão}

O tema da igualdade de gênero como parte integrante das preocupações sobre o trabalho esteve, no século $X X$, entre as principais normas internacionais que regulamentam a relação capital-trabalho. Mesmo que essa temática nunca tenha saído da agenda de discussões, contemporanea- 
mente, a questão do conflito entre trabalho e responsabilidades familiares passa a ter uma importância fundamental para a promoção da igualdade e enfrentamento da pobreza, a partir do "mundo do trabalho".

Nesse momento, lança-se um olhar sobre a normativa internacional, através da OIT, que representa um tipo de consenso quanto aos patamares mínimos acerca da qualidade do trabalho. As normas internacionais do trabalho incluem as Convenções e as Recomendações. Fazemos referência às Convenções da OIT sobre a "Proteção da Maternidade" e sobre "Trabalhadores e Trabalhadoras com Responsabilidades Familiares". Por meio dessas diretrizes, os Estados signatários se comprometem a impulsionar determinadas políticas.

\section{A proteção da maternidade}

Historicamente, o principal vetor das políticas sociais foi o desenvolvimento de ações de ajustamento do padrão de emprego da população economicamente ativa às novas demandas da sociedade urbano-industrial. Nessa direção, segmentos da população considerados vulneráveis para o mercado de trabalho - crianças, mulheres e idosos doentes -, como também desempregados, inválidos e outros - foram beneficiados por importantes mecanismos de proteção e garantia de renda, o que permitiu o enfrentamento da dependência das estritas regras do mercado pela via das políticas públicas, fruto das reivindicações dos trabalhadores.

Após o advento do capitalismo industrial a mulher trabalhadora passou a ser percebida como um "problema social" que necessitava ser enfrentado a partir de intervenção pública. Nesse contexto, os movimentos de mulheres lutaram por um tipo de Estado-providência e um tipo de cidadania que reconhecesse os direitos e as necessidades relacionadas com os riscos não só dos assalariados masculinos, mas também das mães, assalariadas ou não. Eles inspiraram e modelaram uma importante legislação sobre proteção social em diversos países, como licenças e subsídios de maternidade, abono ou salário-família, entre outros. Além disto, contribuía para a proliferação desta legislação o crescente declínio das taxas de fecundidade. A pobreza das famílias e a questão populacional foram as causas mais importantes para a multiplicação das medidas públicas de proteção social à maternidade.

Desde sua fundação, a OIT demonstrou uma constante preocupação com a proteção à maternidade e às mães que trabalham. Diversas Convenções e Recomendações introduziram a maternidade como um bem jurídico tutelado e ampliaram a proteção a todas as mulheres ocupadas em atividades industriais, não industriais e agrícolas, assim como as ocupadas no trabalho doméstico e no trabalho assalariado a domicílio. (OIT, 2006). 
No final da década de 1990, foram realizadas revisões dessas medidas com o objetivo de adaptá-las às condições atuais, em um contexto de globalização econômica, alto desemprego e acordos trabalhistas desfavoráveis aos trabalhadores, dando origem, no ano 2000, à Convenção n. 183 e à Recomendação n. 191. Esta convenção estendeu os direitos a todas as mulheres empregadas, incluindo as que desempenham formas "atípicas" de trabalho dependente. A Convenção tem dois objetivos: defender a saúde das mulheres e de seus filhos e filhas durante a gravidez e a amamentação e, ao mesmo tempo, protegê-las da discriminação que pode afetá-las no local de trabalho por sua condição de mães. Dessa forma, busca-se garantir a igualdade de oportunidades e de tratamento para trabalhadoras e trabalhadores. (OIT, 2010).

O Brasil possui uma disposição legal que protege o emprego durante a maternidade. A CLT e a Constituição Federal prevêem a proteção à maternidade como um direito do trabalho. Essas leis proíbem a demissão em consequência de gravidez e durante os períodos de amamentação. A legislação brasileira prevê a organização do horário de trabalho, mediante a proibição ou proteção quanto ao trabalho noturno e horas extras; tempo livre para realizar consultas médicas durante a gravidez; proibição ou proteção quanto ao trabalho perigoso ou insalubre; redução diária do horário de trabalho para amamentação ou interrupções para amamentação (remuneradas) e instalações adequadas no ambiente de trabalho para a amamentação e guarda das crianças. As medidas de proteção à maternidade contemplam, ainda, a prevenção à exposição aos riscos para a saúde e segurança durante a gravidez e depois dela, o direito à licença-maternidade remunerada, a proteção contra a discriminação no trabalho e a demissão e o direito a voltar ao trabalho após a licença.

Ainda segundo as prescrições da Convenção 183 da OIT, a licençamaternidade deve contemplar três aspectos: um mínimo de 14 semanas de licença, com remuneração de pelo menos $2 / 3$ dos proventos anteriores e custeada pela seguridade social, fundos públicos ou da maneira que determine a legislação nacional quando é o empregador o único responsável pelo seu financiamento. A extensão da licença-maternidade brasileira (17 semanas e $1 \mathrm{dia}$ ) é maior do que a de vários países, entre eles: China (12 semanas); Índia (12 semanas); Alemanha (14 semanas); França (16 semanas); Argentina (12 semanas); México (12 semanas) e Uruguai (12 semanas).

Considerando o previsto na legislação brasileira (CLT), a licençamaternidade é abrangente, maleável, condicionada às condições de saúde da mulher, garantidora da integralidade e estabilidade do salário e do emprego, se comparada a outros países que, muitas vezes, condicionam a integralidade do salário ao tempo de utilização da licença ou, quando a fornecem na sua totalidade, o número de semanas é menor. O problema da legislação brasileira é a sua restrição às trabalhadoras formais e a exigência correlata de contribuição pretérita, excluindo grande parcela de 
trabalhadoras desses direitos, quando não reconhece as múltiplas formas de inserção e o desemprego, com raízes históricas profundas na constituição do mercado de trabalho brasileiro.

Com referência a isso, a emergência das primeiras leis de proteção ao trabalho feminino, no Brasil, apresentava a ideia de que todas as mulheres eram inevitavelmente dependentes e que as assalariadas eram um grupo vulnerável que necessitava de proteção. Como um traço perene da regulamentação do trabalho, as leis que limitavam as horas de trabalho feminino e proibiam o trabalho noturno aplicavam-se eminentemente ao trabalho fabril e àquelas profissões reconhecidas pela lei. Muitas áreas de trabalho foram completamente excluídas, entre as quais a agricultura, o serviço doméstico, os pequenos comércios e outras atividades produtivas de caráter familiar. Isso fez com que a grande maioria das mulheres trabalhadoras não fosse abrangida pela legislação. A associação entre cidadania e ocupação, como descrita por Santos (1994), proporcionou as condições institucionais para que fosse gestado o conceito de mercado informal de trabalho, uma vez que nessas categorias ficaram incluídos os desempregados, os subempregados, os empregados instáveis e os não regulamentados pela lei grande parte destes, mulheres. Como consequência, uma legislação trabalhista sexualmente específica além de não alterar o perfil de inserção feminina no mercado de trabalho sancionou e reforçou a fixação das mulheres a mercados laborais secundários, de salários mais baixos. Os argumentos fortemente assentados no corpo feminino, na obstrução das suas tarefas domésticas e no cuidado com a prole, que configuravam as premissas dessas leis, alargaram o fosso entre o trabalho feminino e masculino. Ao definir o papel reprodutor da mulher como primário, o Estado brasileiro reforçou o estatuto secundário da sua atividade produtiva.

Diferentemente de alguns países já citados, o valor do saláriomaternidade é o valor igual à sua remuneração integral, exceto em outros casos onde esse valor é calculado sobre os últimos salários de contribuição. A trabalhadora desempregada poderá ter direito ao salário-maternidade desde que esteja contribuindo para a Previdência Social. Mais tardiamente, este direito é estendido à mãe adotante, através da Lei n. 10.421, de abril de 2002. (BRASIL, 2002)1.

Ainda no capítulo da Proteção à Maternidade, dois artigos pouco citados nas análises sobre a temática são os de números 394 e 395 da CLT. O primeiro faculta à grávida romper o compromisso resultante do contrato de trabalho, sem previsão de penalidades, quando este for prejudicial à gestação, mediante atestado médico. Nesse artigo, a garantia da saúde materna e infantil se sobrepõe às exigências do contrato formal de trabalho. Por outro lado, o Art. 395 prevê que, apenas em caso de aborto não cri-

1 Disponível em: <http://www.planalto.gov.br/ccivil_03/leis/2002/L10421.htm>. Acesso em: 20 jul. 2010. 
minoso, comprovado por atestado médico oficial, a mulher terá direito a um repouso remunerado de duas semanas (duas semanas de salário-maternidade). Como o aborto no Brasil é crime, exceto em caso de estupro e risco de vida para a mãe, mas uma prática altamente difundida, a legislação trabalhista segue o caráter punitivo e discriminatório do Código Penal, vedando a essas mulheres o direito ao pleno restabelecimento de sua saúde, pelo imediato retorno ao trabalho e contribuindo para aumentar as estatísticas de morbimortalidade materna associada ao aborto.

Ao verificar os direitos, as contrapartidas e a cobertura dos benefícios relacionados à proteção da maternidade, constatamos que, apesar do país se encontrar entre os países com no mínimo 14 semanas de licençamaternidade remunerada e possuir um salário-maternidade que garante a integralidade do salário, a proteção à maternidade exclui grande parcela de trabalhadoras. Deveria ser uma prioridade que todas as trabalhadoras, incluindo aquelas que exercem formas "atípicas" de trabalho tivessem acesso a esta proteção, bem como a necessidade de ampliar aos homens os tipos disponíveis de licença (paternidade, parental e outras), pois são instrumentos eficazes para o fomento à igualdade de gênero.

\section{Medidas legais relativas a trabalho e responsabilidades familiares}

Ao nível internacional, a noção de responsabilidades familiares estava presente em vários documentos da OIT, mas surgiu como preocupação específica, a partir da década de 1960, associada ao avanço das mulheres no mercado de trabalho. Em 1981, o tema é retomado e aprovamse a Convenção e a Recomendação n. 165 sobre Trabalhadores (as) com Responsabilidades Familiares. O debate centrava-se nos seguintes temas: I) os múltiplos papéis assumidos pelas mulheres e II) a necessidade de incorporar os problemas das mulheres trabalhadoras nos esforços globais para a melhoria das condições de trabalho e, também, para tornar realidade o direito de trabalhar sem ser objeto de discriminação. (OIT, 2009). Essa Convenção foi influenciada pela Década das Nações Unidas para a Mulher (1975-1985), incentivando políticas que fossem disponíveis para homens e mulheres: para garantir a ambos o direito ao trabalho sem que suas responsabilidades familiares fossem um obstáculo ou constituíssem fonte de discriminação. A consecução deste objetivo relaciona-se diretamente com a possibilidade de eliminar as barreiras enfrentadas pelas mulheres para se inserir e permanecer no mercado de trabalho. A sobrecarga de trabalho doméstico e as responsabilidades familiares que, por sua vez, as afetam, condicionam e limitam suas trajetórias ocupacionais, sobretudo para as mulheres de domicílios mais pobres. Outro aspecto importante é que quando não se permite aos homens acessar os benefícios associados às responsabilidades familiares, reforça-se o papel doméstico feminino e a expectativa 
de que eles não assumam responsabilidades familiares. É em função disso que a Convenção n. 156 promove a noção de benefícios para homens e mulheres.

A Lei n. 9.799, de 26/05/1999 insere na CLT regras sobre o acesso da mulher ao mercado de trabalho ressaltando os artigos relacionados à igualdade de oportunidades entre homens e mulheres, principalmente, na criação de sanções contra a discriminação das mulheres no mercado de trabalho. Entretanto, a Lei nada prevê para o conflito entre trabalho e responsabilidades familiares. De maneira pontual, há alguns artigos que permitem ao empregado deixar de comparecer ao serviço sem prejuízo do salário e que tem relação com questões familiares. Tais artigos prevêem a ausência do trabalho em caso de falecimento do cônjuge, ascendente, descendente, irmão ou pessoa que viva sob sua dependência econômica; em virtude de casamento e um dia, em caso de nascimento do filho no decorrer da primeira semana. São eventos familiares episódicos e com poucos dias de não comparecimento ao trabalho, não tratam efetivamente do conflito trabalhovida familiar.

A Constituição Federal de 1988, no capítulo da Educação, prevê a Educação Infantil como um direito social e dever do Estado, apesar do pouco avanço em termos da provisão desses serviços. (GAMA, 2012). No entanto, não regulamenta o art. $7^{\circ} \mathrm{e}$, portanto, não define a Educação Infantil como um direito do trabalhador (a). Ainda no art. $7^{\circ}$ da Constituição Brasileira que versa sobre os direitos dos trabalhadores urbanos e rurais, alguns parágrafos foram modificados e merecem destaque: a proibição de diferença salarial por motivo de sexo, idade, cor ou estado civil, que coloca o país em alinhamento com as regulações internacionais do trabalho; a ampliação da licença à gestante, sem prejuízo do emprego e do salário, com a duração de cento e vinte dias; a introdução da licença-paternidade, ainda insuficiente; e a proteção do mercado de trabalho da mulher, mediante incentivos específicos, nos termos da lei. No entanto, a Emenda Constitucional no. 20, de 1988, modifica o salário-família que passa a ser um benefício restrito aos trabalhadores de baixa renda e não mais universal, insuficiente em termos de renda para garantir o seu objetivo e com controles e condicionalidades - exemplo típico das reformas da proteção social brasileira na contemporaneidade. Tendo em vista que os grupos mais vulneráveis são os adultos em idade ativa com filhos e a inexpressividade do salário-família como mecanismo redistributivo, pode-se concluir que as famílias de trabalhadores com crianças encontrar-se-ão majoritariamente desprotegidas.

Os mecanismos legais que até hoje existem no Brasil apresentam muitas deficiências. Em primeiro lugar, tendem a centrar-se em demandas conciliatórias muito específicas, relacionadas à gravidez e à maternidade, desconsiderando que as responsabilidades familiares se referem aos homens e mulheres e que perpassam toda a vida laboral e familiar do (a) trabalhador 
(a), não restrita, portanto, à fase reprodutiva. Em segundo lugar, as formas de acesso aos benefícios e direitos do trabalho estão majoritariamente associadas ao vínculo empregatício e, portanto, restrito aos (as) trabalhadores (as) formais. Logo, é a maioria dos (as) trabalhadores (as) que fica ausente das medidas de proteção social. Uma terceira deficiência se deve à proliferação de medidas de desregulamentação da legislação trabalhista que não contempla a questão do trabalho e responsabilidades familiares.

O Brasil até hoje não ratificou a Convenção sobre Trabalhadores e Trabalhadoras com Responsabilidades Familiares, bem como outras que também possuem relação com essa questão, tais como: a Convenção n. 171 sobre o Trabalho Noturno, de 1990, a Convenção n. 177 sobre o Trabalho no Domicílio, de 1996 e a Convenção n. 175 sobre o Trabalho a Tempo Parcial, de 1994.

Cabe o questionamento, então, de por que o Brasil não subscreveu todas essas normativas. Os motivos são vários e estão interligados. Em primeiro lugar, destacam-se as transformações do mundo do trabalho que se caracterizam como um momento histórico de retração dos direitos do trabalho e sociais. Medidas voltadas à desregulamentação da legislação social e trabalhista adotadas nas décadas de 1990 e 2000 reafirmam a quebra de direitos historicamente conquistados. (MARCONSIN, 2009). Nota-se que essas novas modalidades de contratação e de regimes de trabalho no Brasil desenvolvem-se no mesmo período de tempo em que surgem as convenções citadas, como forma de enfrentamento das refrações da desregulamentação do trabalho no mundo.

Um segundo aspecto que pode ter influenciado a não subscrição das normativas da OIT diz respeito à parca pressão do movimento feminista brasileiro e de outros relacionados, como o sindical, por exemplo. A baixa participação das trabalhadoras nas organizações sindicais e nas suas direções e a falta de lideranças capacitadas para negociações coletivas que pressionem pela realização desses direitos são alguns dos motivos que podem ser elencados.

Por fim, são sérias as dificuldades para que essas demandas sejam veiculadas em um contexto de ajuste estrutural e diminuição do gasto público em políticas sociais, com proposições assentadas no pluralismo de bemestar, no ideário da corresponsabilidade social e no deslocamento do protagonismo do Estado para a família na provisão de proteção social. Nesse contexto, além de tais mecanismos legais não serem subscritos, eles não seriam suficientes sem medidas de acompanhamento e fiscalização desses direitos e de setores organizados da sociedade preocupados e focados na reivindicação dessas temáticas.

\section{As proposições do legislativo}

Com o intuito de captar algumas tendências das demandas da sociedade sobre o conflito entre trabalho e responsabilidades familiares, 
analisamos a apresentação e tramitação de projetos de lei no legislativo brasileiro. Se esses projetos serão aprovados e transformados em lei foge ao escopo deste trabalho, mas a iniciativa dessa sistematização visa apresentar a natureza do debate desenvolvido no legislativo brasileiro. Essas informações foram buscadas através do site do Centro Feminista de Estudos e Assessoria (CFEMEA). O levantamento foi realizado no período compreendido entre os anos de 1994 e $2010^{2}$.

Procuramos discutir essas proposições à luz de uma concepção complexa de igualdade de gênero como um critério normativo, no sentido de um parâmetro para avaliar as propostas. (FRASER, 1997). A igualdade de gênero, segundo este autor, é composta por sete princípios normativos distintos, a saber: o da antipobreza, o da antiexploração, o da igualdade de renda, o da igualdade de tempo livre, o da igualdade de respeito, da antimarginalização e do antiandrocentrismo. O objetivo, então, adaptado aos interesses do estudo é construir uma análise das proposições do legislativo baseada na maximização da satisfação de todos esses princípios ou pelo menos da maioria deles. Neste sentido, os critérios estabelecidos para o indicador Igualdade de Gênero (IG) utilizados neste trabalho foram:

1 - Fomenta a repartição do trabalho doméstico não remunerado entre os gêneros;

2 - Amplia o gozo de direitos relacionados a trabalho e responsabilidades familiares;

3 - Garante direitos iguais ou ajuda a promovê-los entre homens e mulheres no mercado de trabalho e no trabalho doméstico não remunerado;

4 - Equilibra os diferenciais de renda entre os sexos;

5 - Acesso universal, ao preconizado na Lei, independente do vínculo empregatício do (a) trabalhador (a);

6 - Repara diferenciais legais anteriormente existentes entre homens e mulheres e entre mulheres;

7 - Visa à promoção da diminuição da pobreza.

Estabelecemos três níveis de caracterização do indicador Igualdade de Gênero. Ela é Desenvolvida (D) quando contempla a partir de 4 dos critérios estabelecidos, Moderada (M) quando contempla 2-3 critérios e Insuficiente (I) quando contempla 1 ou nenhum dos critérios acima. Importante sinalizar que nem todas as proposições legais visam todos os critérios constituídos, mas na análise do espírito da lei podemos encontrar mais critérios do que aqueles originalmente pretendidos.

Em termos gerais, constatamos a ausência de problematização específica sobre a temática do conflito entre trabalho e família, mantendo a inexistência de políticas públicas direcionadas a este fim.

\footnotetext{
${ }_{2}$ Conferir em <http://www.cfemea.org.br>.
} 
O tema trabalho foi aquele com maior concentração de propostas, totalizando 33 em diferentes subtemas.

A distribuição partidária foi altamente diversificada, em termos de partidos considerados progressistas ou conservadores.

Um dado que chamou a atenção foi a concentração de proposições oriundas de parlamentares das regiões Norte, Nordeste e CentroOeste do país. Considerando que a representação parlamentar no Brasil é proporcional por estados, visando à equanimidade entre aqueles mais e menos populosos e a despeito das críticas que se coloquem a esse fundamento, surpreende o número de proposições dos estados dessas regiões relacionadas ao trabalho feminino, principalmente, quando as indicações de maior participação feminina no mercado de trabalho são originárias das regiões Sul e Sudeste do país.

Houve certa paridade na origem das propostas, Câmara dos Deputados e Senado Federal, considerando o maior número de parlamentares na primeira Casa, assim como em termos da distribuição de sexo dos parlamentares, visto que as mulheres são minoritárias em ambas as casas legislativas. Em resumo, não encontramos diferencial importante no gênero dos parlamentares, na origem institucional e partidária dos projetos de lei.

Encontramos nesse primeiro bloco (conforme Quadros 1 e 2) um conjunto majoritário de proposições que se concentra na inclusão de beneficiários em leis já existentes, no caso os homens (pais) detentores de guarda de filhos portadores de deficiências físicas e/ou mentais. Nota-se uma maior preocupação na relação entre trabalho e adoecimento de crianças na família, sinalizando para a questão do cuidado na família. Verifica-se, ainda, outro conjunto importante que visa estabelecer leis e/ou regulamentá-las no sentido de garantir a estabilidade no emprego, ainda que muito restrita às mulheres, e a redução da jornada de trabalho relacionada às demandas da vida familiar. Duas proposições se destacam por serem inovações que tendem a uma maior universalização dos direitos, a possibilidade de inclusão das desempregadas e a disposição sobre a licençaparental. Outra iniciativa que teria impacto em termos da renda das famílias é a desoneração do imposto de renda no salário-educação e no saláriomaternidade. No geral, são propostas medianas em face dos critérios da igualdade de gênero, principalmente, pela ausência do acesso universal independente do vínculo empregatício e do gênero do (a) trabalhador (a).

Os projetos de lei, apresentados no Quadro 3, se caracterizam por proposições muito específicas, direcionadas a situações especiais. A insuficiência das propostas segundo o parâmetro da Igualdade de Gênero foi a tônica encontrada, seja porque pouco contribuem para a diminuição da precarização do trabalho feminino, seja porque mantém padrões anteriores de desigualdade entre os gêneros. Destaque, entretanto, para os projetos que visam a proteger a saúde das mulheres nos locais de trabalho, incluindo aí os acidentes, e aqueles que dispõem sobre a redução da jornada 
de trabalho para 40 horas semanais que, notadamente, apresentam efeitos sobre o conflito entre trabalho e responsabilidades familiares. Ressalta-se, ainda, a importância dos projetos de lei que estabelecem punição contra a desigualdade salarial entre homens e mulheres, mesmo sendo este um padrão ainda recorrente no mercado de trabalho brasileiro.

\section{Quadro 1 - Licença maternidade/ paternidade/ adoção - 14 propostas}

\begin{tabular}{|c|c|c|c|c|c|}
\hline Ementa & Partido/UF & Origem & $\begin{array}{c}\text { Sex } \\
0\end{array}$ & Cobertura & IG \\
\hline $\begin{array}{l}\text { Ampliaçâo da licença-gestante para } 180 \text { dias alterando o } \\
\text { art. } 7^{\circ} \text {, da Constituição Federal. }\end{array}$ & $\begin{array}{l}\text { PT/RR } \\
\text { DEM/RN }\end{array}$ & $\begin{array}{l}\mathrm{CD} \\
\mathrm{SF}\end{array}$ & $\begin{array}{c}\mathrm{Fe} \\
\mathrm{F}\end{array}$ & $\begin{array}{l}\text { Universal } \\
\left(\mathrm{EF}^{3}\right)\end{array}$ & $\begin{array}{l}1 \\
2\end{array}$ \\
\hline $\begin{array}{l}\text { Garante a estabilidade do pai no emprego, desde a } \\
\text { confirmação da gravidez da mulher até } 4 \text { meses após o } \\
\text { parto, quando ele é a única fonte de renda familiar; idem, } \\
\text { mas sem especificar que o pai seja o único provedor. }\end{array}$ & $\begin{array}{l}\mathrm{PDT} / \mathrm{RJ} \\
\mathrm{PT} / \mathrm{SP}\end{array}$ & $\begin{array}{l}C D \\
C D\end{array}$ & $\begin{array}{l}M \\
M\end{array}$ & $\begin{array}{l}\text { Universal } \\
\text { (EF) } \\
\text { Universal } \\
\text { (EF) }\end{array}$ & $\begin{array}{c}M \\
1,2,7 \\
M \\
1,2\end{array}$ \\
\hline $\begin{array}{l}\text { Isenção do Imposto sobre a renda dos valores recebidos a } \\
\text { título de salário-educação e salário-maternidade }\end{array}$ & PMDB/MT & SF & M & $\begin{array}{l}\text { Universal } \\
\text { (EF) }\end{array}$ & $\begin{array}{c}M \\
2,6\end{array}$ \\
\hline $\begin{array}{l}\text { Regulamenta a licença-paternidade a que se refere o art. } \\
7^{\circ} \text {. da CF. }\end{array}$ & $\mathrm{PDT} / \mathrm{CE}$ & SF & $F$ & $\begin{array}{l}\text { Universal } \\
\text { (EF) }\end{array}$ & $\begin{array}{c}D \\
1,2,3,6\end{array}$ \\
\hline $\begin{array}{l}\text { Nova redação para licença-maternidade, paternidade e } \\
\text { cria estabilidade provisória no emprego, proteção da } \\
\text { maternidade, da adoção e da infância. }\end{array}$ & $\mathrm{PT} / \mathrm{SP}$ & $\mathrm{CD}$ & M & $\begin{array}{l}\text { Universal } \\
\text { (EF) }\end{array}$ & $\begin{array}{c}D \\
1,2,3,6\end{array}$ \\
\hline $\begin{array}{l}\text { Nova redação à Lei } 11.770 / 2008 \text { que cria o Programa } \\
\text { Empresa Cidadã para ampliar a licença-paternidade em } 30 \\
\text { dias, caso a mãe não trabalhe em empresa participante. }\end{array}$ & $\mathrm{PMDB} / \mathrm{ES}$ & $\mathrm{CD}$ & $\mathrm{F}$ & Focalizada & $\begin{array}{c}M \\
1,2\end{array}$ \\
\hline Dispõe sobre a licença-parental, (CLT) & $\mathrm{PSB} / \mathrm{CE}$ & SF & M & Universal & $\begin{array}{c}D \\
1,2,3,6\end{array}$ \\
\hline $\begin{array}{l}\text { Dispõe sobre a redução da jornada de trabalho para os } \\
\text { pais (H e M) ou detentores de guarda judicial de filho } \\
\text { portador de deficiência física ou mental grave. }\end{array}$ & PT/RS & $\mathrm{CD}$ & $F$ & Focalizada & $\begin{array}{c}M \\
1,2,3\end{array}$ \\
\hline $\begin{array}{l}\text { Dá nova redação em artigos da Lei } 8213 / 91 \text { para permitir } \\
\text { a concessão de salário-maternidade à segurada } \\
\text { desempregada. }\end{array}$ & $\mathrm{PMDB} / \mathrm{RO}$ & CD & $F$ & Universal & $\begin{array}{c}\text { D } \\
2,5,6,7\end{array}$ \\
\hline $\begin{array}{l}\text { Estende os direitos assegurados à trabalhadora gestante, } \\
\text { nos casos de morte desta, a quem detiver a guarda de seu } \\
\text { filho. }\end{array}$ & $\mathrm{PMDB} / \mathrm{RO}$ & CD & F & Universal & $\begin{array}{c}M \\
2,3,6\end{array}$ \\
\hline $\begin{array}{l}\text { Dispõe sobre falta justificada de pais (H e M) de crianças } \\
\text { portadoras de deficiência física para acompanhamento de } \\
\text { terapias e tratamentos médicos. Acompanhar filho em } \\
\text { virtude de enfermidade. (CLT) }\end{array}$ & $\begin{array}{l}\mathrm{PTB} / \mathrm{SP} \\
\mathrm{PSB} / \mathrm{RN}\end{array}$ & $\begin{array}{l}C D \\
C D\end{array}$ & $\begin{array}{l}M \\
F\end{array}$ & $\begin{array}{l}\text { Universal } \\
\text { (EF) } \\
\text { Universal }\end{array}$ & $\begin{array}{c}M \\
1,2,3 \\
D \\
1,2,3,6\end{array}$ \\
\hline $\begin{array}{l}\text { Veda a dispensa arbitrária ou sem justa causa do } \\
\text { trabalhador cuja esposa ou companheira gestante nào } \\
\text { goze do mesmo benefício; acrescenta indenização e multa } \\
\text { sobre a matéria. }\end{array}$ & $\begin{array}{l}\mathrm{PTB} / \mathrm{AM} \\
\mathrm{PP} / \mathrm{GO} \\
\mathrm{PC} \text { do B / } \\
\text { AM }\end{array}$ & $\begin{array}{l}C D \\
C D \\
C D\end{array}$ & $\begin{array}{l}M \\
M \\
F\end{array}$ & $\begin{array}{l}\text { Universal } \\
\text { (EF) }\end{array}$ & $\begin{array}{c}M \\
2,3\end{array}$ \\
\hline $\begin{array}{l}\text { Acrescenta art. para dispor sobre a estabilidade provisóría } \\
\text { da empregada gestante, ainda que constatada a gravidez } \\
\text { no periodo de aviso prévio. }\end{array}$ & $\mathrm{PMDB} / \mathrm{RO}$ & SF & M & $\begin{array}{l}\text { Universal } \\
\text { (EF) }\end{array}$ & $\begin{array}{c}M \\
2,6\end{array}$ \\
\hline $\begin{array}{l}\text { Altera Ato das Disposições Constitucionais para dispor } \\
\text { sobre a estabilidade da empregada gestante. }\end{array}$ & PSOL/AL & SF & $\mathrm{F}$ & $\begin{array}{c}\text { Universal } \\
\text { (EF) }\end{array}$ & $\begin{array}{c}M \\
2,6\end{array}$ \\
\hline $\begin{array}{l}\text { Dispõe sobre concessão de estabilidade provisória aos } \\
\text { genitores, únicos provedores de renda da familia. }\end{array}$ & PT/RR & SF & $M$ & Focalizada & $\begin{array}{c}M \\
1,2,7\end{array}$ \\
\hline $\begin{array}{l}\text { Assegurar à mulher sob estabilidade provisória a } \\
\text { continuidade do beneficio em caso de falecimento do } \\
\text { filho. (CLT) }\end{array}$ & $\mathrm{PMDB} / \mathrm{MT}$ & CD & M & Universal & $\begin{array}{l}1 \\
2\end{array}$ \\
\hline
\end{tabular}

Fonte: <http://wwww.cfemea.org.br>.

${ }^{3} \mathrm{EF}=$ Emprego Formal 


\section{Quadro 2 - Outros - 03 propostas}

\begin{tabular}{|l|c|c|c|c|c|}
\hline \multicolumn{1}{|c|}{ Ementa } & Partido/UF & Origem & Sexo & Cobertura & IG \\
\hline $\begin{array}{l}\text { Estabelece a obrigatoriedade da instalação de creche e pré- } \\
\text { escola nas unidades de segurança pública. }\end{array}$ & PSB/ES & CD & M & Focalizado & M \\
\hline $\begin{array}{l}\text { Amplia o período de interrupção do contrato de trabalho em } \\
\text { razão de casamento para até cinco dias consecutivos e } \\
\begin{array}{l}\text { estende o beneficio aos empregados que tenham } \\
\text { formalizado união estável. (CLT) }\end{array}\end{array}$ & PR/RO & SF & M & Universal & M \\
\hline $\begin{array}{l}\text { Cria Programa Nacional de Inclusão ao mercado de trabalho } \\
\text { das mulheres beneficiadas pelo programa Bolsa Familia. }\end{array}$ & PMDB/RI & CD & F & Focalizado & I \\
\hline
\end{tabular}

Fonte: <http://wwww.cfemea.org.br>.

\section{Quadro 3 - Proteção/precarização do trabalho das mulheres - 09 propostas}

\begin{tabular}{|c|c|c|c|c|c|}
\hline Ementa & Partido/UF & Origem & Sexo & Cobertura & IG \\
\hline $\begin{array}{l}\text { Estabelece incentivo fiscal às empresas que contratarem } \\
\text { empregadas mulheres chefes de familia. }\end{array}$ & $\mathrm{PT} / \mathrm{PI}$ & $C D$ & $M$ & Focalizado & $\begin{array}{l}1 \\
2\end{array}$ \\
\hline $\begin{array}{l}\text { Altera art. lei } 8.213 / 91 \text { para estender } o \text { auxílio-acidente às } \\
\text { seguradas que tiverem filhos prematuros, em virtude de } \\
\text { acidente de trabalho, desde que demandem cuidados } \\
\text { especiais. }\end{array}$ & PV/SP & $C D$ & $M$ & $\begin{array}{l}\text { Universal } \\
\text { (EF) }\end{array}$ & $\begin{array}{l}1 \\
2\end{array}$ \\
\hline $\begin{array}{l}\text { Autoriza o Poder Executivo a adotar medidas de apoio aos } \\
\text { servidores responsáveis por portadores de deficiências } \\
\text { fisicas, sensoriais ou mentais. }\end{array}$ & $\mathrm{PMDB} / \mathrm{GO}$ & SF & $M$ & Focalizado & $\begin{array}{c}M \\
1,2\end{array}$ \\
\hline $\begin{array}{l}\text { Dispóe sobre a realização de serviços voluntários pelas } \\
\text { mães empregadas, nas creches ou locais para guarda dos } \\
\text { filhos, no período de amamentação, mantido pelas } \\
\text { empresas. (CLT). }\end{array}$ & $\mathrm{PMDB} / \mathrm{GO}$ & $\mathrm{CD}$ & $\mathrm{F}$ & Universal & I \\
\hline $\begin{array}{l}\text { Prevê punição e mecanismos de fiscalização contra a } \\
\text { desigualdade salarial entre homens e mulheres. (CLT) }\end{array}$ & PSOL/RS & $\mathrm{CD}$ & $F$ & Universal & $\begin{array}{c}M \\
4,6\end{array}$ \\
\hline $\begin{array}{l}\text { Estabelecer multa para combater a diferença de } \\
\text { remuneração entre homens e mulheres. (CLT) }\end{array}$ & PMDB/MS & $\mathrm{CD}$ & $M$ & Universal & $\begin{array}{c}M \\
4,6\end{array}$ \\
\hline $\begin{array}{l}\text { Dispõe sobre a jornada de trabalho de } 40 \text { horas semanais. } \\
\text { Altera o art. } 7^{\circ} \mathrm{CF} \text { reduzindo a jornada máxima de trabalho } \\
\text { para } 40 \text { horas semanais e aumenta para } 75 \% \text { a } \\
\text { remuneração de serviço extraordinário. }\end{array}$ & $\begin{array}{c}\text { PT/RS } \\
\text { PC do } B / C E\end{array}$ & $\begin{array}{l}\mathrm{CD} \\
\mathrm{CD}\end{array}$ & $\begin{array}{l}M \\
M\end{array}$ & Universal & $\begin{array}{c}\text { D } \\
1,2,3,6\end{array}$ \\
\hline $\begin{array}{l}\text { Proibe o trabalho da gestante ou lactante em atividades, } \\
\text { operaçoes ou locais insalubres. }\end{array}$ & $\mathrm{PP} / \mathrm{GO}$ & $C D$ & $M$ & Universal & $\begin{array}{c}M \\
2,7\end{array}$ \\
\hline Cria a profissão de cuidador. & $\mathrm{PR} / \mathrm{PE}$ & $C D$ & M & Focalizado & 1 \\
\hline
\end{tabular}

Fonte: <http://wwww.cfemea.org.br>.

Nas proposições referentes à Previdência Social, encontramos duas trajetórias distintas (Quadro 4). Na primeira delas, destacam-se os projetos que combatem a desigualdade de renda entre as mulheres, principalmente para o tipo de família que encontra as maiores pressões para satisfazer as demandas entre trabalho e vida familiar - as famílias monoparentais femininas. Outro projeto importante que se relaciona com o conflito discutido é aquele que gera renda para a família, através de benefício, em caso de adoecimento de dependente e que possibilita a ausência do trabalhador nestes casos. Os efeitos dessas leis para aqueles mais afetados pelas demandas familiares seriam contundentes. 


\section{Quadro 4 - Previdência Social - Total: 04 propostas}

\begin{tabular}{|c|c|c|c|c|c|}
\hline Ementa & Partido/UF & Origem & Sexo & Cobertura & IG \\
\hline $\begin{array}{l}\text { Altera a redação dos art.16 e } 77 \text { da lei } 8.213 \text { para } \\
\text { aumentar para } 24 \text { anos o limite de idade até o qual os } \\
\text { filhos e irmãos de segurados do Regime Geral de } \\
\text { Previdencia Social podem ser considerados seus } \\
\text { dependentes. }\end{array}$ & $\mathrm{PDT} / \mathrm{DF}$ & SF & $M$ & $\begin{array}{c}\text { Universal } \\
\text { (EF) }\end{array}$ & $\begin{array}{l}1 \\
2\end{array}$ \\
\hline $\begin{array}{l}\text { Cria o auxilio-doença de dependente menor e autoriza a } \\
\text { falta do trabalhador quando fizer jus ao auxílio-doença, } \\
\text { auxílio-acidente e auxilio-doença de dependente menor. }\end{array}$ & $\mathrm{PMDB} / \mathrm{PE}$ & $\mathrm{CD}$ & $M$ & $\begin{array}{l}\text { Universal } \\
\text { (EF) }\end{array}$ & $\begin{array}{c}\text { D } \\
1,2,3,7\end{array}$ \\
\hline $\begin{array}{l}\text { Acrescenta parag. } 6^{\circ} \text { a art. da lei } 8.900 / 94 \text { para ampliar a } \\
\text { quantidade de parcelas do seguro-desemprego paga à } \\
\text { mulher arrimo de familia. }\end{array}$ & PT/SP & CD & $M$ & Focalizado & $\begin{array}{c}M \\
2,6,7\end{array}$ \\
\hline Assegura a licença-matemidade para a adotante & PT/RS & SF & $M$ & Universal & $\begin{array}{c}M \\
2,6\end{array}$ \\
\hline
\end{tabular}

Fonte: <http://wwww.cfemea.org.br>.

A segunda linha de proposições é mais polêmica, pois trata eminentemente da inclusão da dona de casa como beneficiária da Previdência Social e de benefícios não contributivos (Quadro 5). Apesar de indicar uma disposição para a garantia de renda e por consequência de diminuição da pobreza extrema, pela inclusão das donas de casa no regime previdenciário, essas propostas de lei não contribuem para a autonomia das mulheres ao longo da vida, engessa o papel tradicional das mulheres no trabalho doméstico e reforça o atrelamento ao vínculo marital de dependência econômica. Ademais, uma das propostas é repetitiva quanto àqueles que têm direito ao Benefício de Prestação Continuada (BPC).

$$
\text { Quadro } 5 \text { - Trabalho Doméstico - Total: } 03 \text { propostas }
$$

\begin{tabular}{|l|c|c|c|c|c|}
\hline \multicolumn{1}{|c|}{ Ementa } & Partido/UF & Origem & Sexo & Cobertura & IG \\
\hline $\begin{array}{l}\text { Regulamenta parágrafos e artigos para dispor sobre o sistema } \\
\text { especial de inclusão previdenciária dos trabalhadores de baixa } \\
\text { renda e daqueles que, sem renda própria, se dedicam } \\
\text { exclusivamente ao trabalho doméstico e sobre a contribuição } \\
\text { social das empresas. }\end{array}$ & PT/RS & SF & M & Universal & M \\
\hline $\begin{array}{l}\text { Acrescenta parágrafo ao art. 21 da lei 8212/91 para permitir que } \\
\text { a dona de casa recolha contribuição previdenciária desde o } \\
\text { casamento. }\end{array}$ & PSDB/SP & CD & M & Universal & I \\
\hline $\begin{array}{l}\text { Cria beneficio assistencial de renda mínima no valor de um SM, } \\
\text { sem acúmulo com outro beneficio previdenciário ou } \\
\text { assistencial, exceto pensão por morte, a ser deferido às donas } \\
\text { de casa que completem } 60 \text { anos de idade, independente da } \\
\text { comprovação ou recolhimento da contribuição. }\end{array}$ & PT/SC & CD & F & Universal & I \\
\hline
\end{tabular}

Fonte: <http://wwww.cfemea.org.br>.

Os projetos de lei relacionados ao capítulo da Educação foram aqueles com a maior inclinação universalizante. Acima de tudo, preconizam a universalidade e gratuidade da Educação Infantil como um direito das crianças e um direito do(a) trabalhador(a). Em termos de políticas relacionadas ao conflito 
entre trabalho e responsabilidades familiares são as propostas que podem ser consideradas as mais eficazes.

\section{Considerações finais}

As características históricas da constituição de políticas sociais no Brasil relacionadas ao conflito entre trabalho e responsabilidades familiares apresentam um traço fundamental: o padrão de estruturação do mercado de trabalho típico da exploração de classe no Brasil, que segmenta trabalhadores e que conecta os direitos do trabalho a essa estrutura desigual.

Não há no Brasil uma política direcionada à conjugação das necessidades laborais e familiares. A ampla oferta do emprego doméstico no Brasil, a segmentação do mercado de trabalho que alija dos direitos do trabalho grande parte da massa trabalhadora dão uma tonalidade específica às condições de produção e reprodução social atravessada pelas relações de classe. Ocorre que, atualmente, as próprias condições de produção do trabalho doméstico não remunerado estão alteradas pela inserção feminina no mercado de trabalho, pela pouca variabilidade da divisão sexual do trabalho no interior da família, pelas mudanças nas estruturas familiares que requerem novos aportes sociais relativos ao trabalho, aos direitos do trabalhador, ao papel do Estado e às possibilidades de ampliação dos direitos sociais. As famílias estão exauridas. Apesar da diminuição dos índices de pobreza nos anos recentes e de algumas alterações no padrão de desestruturação do mercado de trabalho que marcou a década de 1990, tais mudanças não diminuíram os conflitos entre a vida laboral e familiar. As terceirizações incrementaram a informalidade, os salários das mulheres são, ainda, consideravelmente menores do que o dos homens, os benefícios trabalhistas estão altamente associados à formalização do emprego, possuem um forte viés de gênero, estão concentrados nos direitos reprodutivos das mulheres e não como demandas familiares permanentes ao longo do ciclo de vida dos (as) trabalhadores (as).

O que a luta feminista não esperava ao reivindicar a inserção no mundo do trabalho como um mecanismo de emancipação feminina era que o capitalismo com sua enorme capacidade de mutação e adaptabilidade absorveria a entrada das mulheres no mercado de trabalho de modo a incrementar a exploração do trabalho de todas/os no processo de acumulação. Além disso, o abandono de uma reflexão teórica e política da indissociabilidade entre trabalho e reprodução social tem como consequência o avanço da desvalorização social da esfera da reprodução, desfocando a degradação do trabalho para homens e mulheres e seu impacto no conjunto da vida social, notadamente, no âmbito familiar.

A instabilidade e a heterogeneidade do mercado de trabalho brasileiro associado à permanência do trabalho doméstico não remunerado 
trazem, no tocante ao aumento do bem-estar do (a) trabalhador (a) e a proteção da família, a transformação de direitos trabalhistas em direitos universais. Porém, com a crescente precarização do trabalho, Fraser (1997) ousa ainda mais ao propor que as reivindicações sobre o trabalho sejam reorientadas pelas necessidades da reprodução. Isto implica em menores jornadas de trabalho, sem perda de direitos, universalização das políticas sociais e equiparação do status do trabalho, do cuidado ao âmbito da produção. Com o seu caráter utópico, tais propostas são uma via inspiradora para homens e mulheres inseridos em uma lógica de produção e reprodução social desumanizadora das relações sociais. 


\section{ReVista all paUtg}

\} TRABALHO E RESPONSABILIDADES FAMILIARES NO BRASIL - GAMA, A. S.\}

\section{Referências}

BRASIL. Casa Civil. Lei n.10.421, de 15 de abril de 2002. Estende à mãe adotiva o direito à licença-maternidade e ao salário-maternidade, alterando a Consolidação das Leis do Trabalho, aprovada pelo Decreto-Lei n. 5.452, de $1^{\circ}$ de maio de 1943, e a Lei n. 8.213, de 24 de julho de 1991. Diário Oficial da União Disponível em: <http://www.planalto.gov.br/ccivil_03/ leis/2002/L10421.htm>. Acesso em: 20 jul. 2010.

BRASIL. Casa Civil. Decreto-lei n. 5.452, de $1^{\circ}$ de maio de 1943. Aprova a Consolidação das Leis do Trabalho. Disponível em: <http://www.pla nalto.gov.br/ccivil/decreto-lei/del5452compilado.htm>. Acesso em: 22 jul. 2010.

BRASIL. Constituição da República Federativa do Brasil: 4a. ed. São Paulo: Saraiva, 1990.

BRUSCHINI, C.; LOMBARDI, M.R. Mulheres e homens no mercado de trabalho brasileiro: um retrato dos anos 1990. In: MARUANI, M.; HIRATA, H. (Orgs.) As novas fronteiras da desigualdade: homens e mulheres no mercado de trabalho. São Paulo: SENAC-SP, 2003, p. 323-361.

CENTRO FEMINISTA DE ESTUDOS E ASSESSORIA (CFEMEA). Disponível em: <http://www.cfemea.org.br>. Acesso em: 16 jun. 2010.

FRASER, N. After the family wage: a postindustrial thought experiment. In: FRASER, N. Justice interruptus: critical reflections on the "postsocialist" condition. New York: Routledge, 1997, p. 41-66.

GAMA, A. S. O conflito entre trabalho e responsabilidades familiares no Brasil: reflexões sobre os direitos do trabalho e a política de educação infantil. Rio de Janeiro, Tese (Doutorado) - Programa de Pós-Graduação em Saúde Pública, ENSP/FIOCRUZ, 2012.

HIRATA, H. Reorganização da produção e transformações do trabalho: uma nova divisão sexual? In: BRUSCHINI, C; UNBEHAUM, S.G. (Org.) Gênero, democracia e sociedade brasileira. São Paulo: Editora 34, 2002, p. 339-355.

MARCONSIN, C. Cerco aos direitos trabalhistas e crise do movimento sindical no Brasil contemporâneo. Rio de Janeiro, Tese (Doutorado) - Programa de Pós-Graduação em Serviço Social, UFRJ, 2009.

McINTOSH, M. Feminism and social policy. In: PIERSON, C.; CASTELS, F.G. (eds.). The welfare state reader. Cambridge: Polity Press, 2000, p. 119131.

MELO, H.P. Globalização, políticas neoliberais e relações de gênero no Brasil. In: BORBA, A.; FARIA, N.; GODINHO, T. (Orgs.). Mulher e política: 


\section{Revistg ell paUtg}

\} TRABALHO E RESPONSABILIDADES FAMILIARES NO BRASIL - GAMA, A. S.\}

gênero e feminismo no Partido dos Trabalhadores. São Paulo: Fundação Perseu Abramo, 1998.

OFICINA INTERNACIONAL DEL TRABAJO (OIT). Promoviendo la igualdad de género. Convenios de la OIT y los derechos laborales. Santiago: OIT, 2006.

ORGANIZAÇÃO INTERNACIONAL DO TRABALHO. Negociação coletiva de trabalho e equidade de gênero e raça no Brasil. Brasília: OIT, 2009.

OFICINA INTERNACIONAL DEL TRABAJO (OIT). La maternidad en el trabajo: examen de la legislación nacional. 2a. Ed. Genebra: OIT, 2010.

PATEMAN, C. O contrato sexual. Rio de Janeiro: Paz e Terra, 1993.

SANTOS, W. G. Cidadania e justiça: a política social na ordem brasileira. Rio de Janeiro: Campus, 1994.

Recebido em 12 de outubro de 2012.

Aprovado para publicação em 14 de dezembro de 2012. 